\title{
Kinesio taping - a healing and supportive method in various fields of medicine, dentistry, sport and physiotherapy
}

Authors' Contribution: A Study Design B Data Collection C Statistical Analysis D Data Interpretation E Manuscript Preparation F Literature Search G Funds Collection

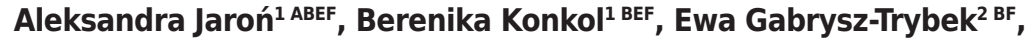 \\ Joanna Bladowska ${ }^{3 \text { BF }}$, Anna Grzywacz ${ }^{4 \text { BF, Armin Nedjat }}{ }^{5}$, Grzegorz Trybek ${ }^{1}$ ABEF \\ ${ }^{1}$ Department of Oral Surgery, Pomeranian Medical University in Szczecin, Poland \\ 2 Department of Diagnostic Imaging and Interventional Radiology, \\ Pomeranian Medical University in Szczecin, Poland \\ ${ }^{3}$ Department of General Radiology, Interventional Radiology and Neuroradiology, \\ Wroclaw Medical University, Wroclaw, Poland \\ ${ }^{4}$ Independent Laboratory of Health Promotion, \\ Pomeranian Medical University in Szczecin, Poland \\ ${ }^{5}$ Champions-Implants GmbH, Flonheim, Germany
}

\section{abstract}

Kinesio taping (KT) is a method of elastic taping, created in the 1970 s by a Japanese chiropractor, Dr. Kenzo Kase. The aim of this study was to present KT techniques and its application in various fields of medicine, sports and rehabilitation. The publications used in this paper were sourced from the PubMed and the Google Scholar databases. The keywords used to search databases included KT, Kinesio taping, medicine, dentistry and sport. Based on this study, it can be concluded that $K T$ is the most recommendable method. Its use is being increasingly popular in many fields of medicine. It can be considered as an alternative for painkillers, especially in patients for whom the use of painkillers is not advisable or ineffective due to their condition. $\mathrm{KT}$ is well tolerated by patients and saves time; therefore, its use should be taken into account in various medical environments. In order to use this method, one should complete specialized courses, which, on the one hand, provide theoretical basis for its use, and on the other hand, teach how to choose original tapes in a practical way, as well as apply appropriate techniques in order to observe and compare the effects of one's work - therapy and treatment.

Key words: Kinesio taping, medicine, oral surgery, dentistry, rehabilitation, Kinesiology taping.

\section{article details}

Article statistics: Word count: 4,913; Tables: 2; Figures: 11; References: 42

Received: March 2021; Accepted: April 2021; Published: June 2021

Full-text PDF:

http://www.balticsportscience.com

Copyright @ Gdansk University of Physical Education and Sport, Poland

Indexation: Celdes, Clarivate Analytics Emerging Sources Citation Index (ESCI), CNKI Scholar (China National Knowledge Infrastructure), CNPIEC, DOAJ, EBSCO - Central \& Eastern European Academic Source, EBSCO - SPORTDiscus, EBSCO Discovery Service, Google Scholar, Index Copernicus, J-Gate, Naviga (Softweco, Primo Central (ExLibris), ProQuest - Family Health, ProQuest - Health \& Medical Complete, ProQuest - Illustrata: Health Sciences, ProQuest Nursing \& Allied Health Source, Summon (Serials Solutions/ProQuest, TDOne (TDNet), Ulrich's Periodicals Directory/ ulrichsweb, WorldCat (OCLC)

Funding: This research received no specific grant from any funding agency in the public, commercial, or not-for-profit sectors.

Conflict of interests: Authors have declared that no competing interest exists.

Corresponding author: Aleksandra Jaroń; Department of Oral Surgery, Pomeranian Medical University in Szczecin; e-mail: jaronola@gmail.com; ORCID: 0000-0001-7727-6388

Open Access License: This is an open access article distributed under the terms of the Creative Commons Attribution-Non-Commercial-NoDerivatives 4.0 International (https://creativecommons.org/licenses/by-nc-nd/4.0/), which permits use, distribution and reproduction in any medium, provided the original work is properly cited, the use is non-commercial and is otherwise in compliance with the license. 


\section{INTRODUCTION}

Kinesio taping (KT) is a method of elastic taping, created in the 1970s by a Japanese chiropractor, Dr. Kenzo Kase. While working with various sports players, he noticed that immediately after inelastic tape was applied, undesired reactions - triggered by pressure - occurred in places where injuries were situated [1]. As a result of his observations, Dr. Kenzo - together with engineers from the field of medical biotechnology - designed an elastic band that mimics elasticity of the human skin and has similar properties (Table 1). Consequently, the method of this therapy was termed Kinesio Taping [1]. Moreover, Dr. Kenzo Kase suggested that depending on how this elastic tape is applied, it can lead to a reduction in pain and swelling, mechanical correction or support, as well as an improvement in the muscle activity or functional proprioceptive stimulation [2]. Over the years, the method has become increasingly popular among specialists including physical therapists, sports therapists, chiropractors, osteopaths and sports trainers [3]. Dynamic taping - as one of many therapeutic methods - has a wide range of applications in medicine, sports or even podology [3]. The Polish publications on this particular method use such terms as kinesiology taping and kinesio taping - KT [4, 5]. Furthermore, a wider interest in kinesio taping was developed after the 1990 Olympics in Japan, where KT was used by a Dutch volleyball player [6]. In Poland, the method was first applied in 2002 in Pabianice, following the first basic course in kinesio taping led by Cosimo Bruno from Italy [6]. Educating 21 instructors who became certified by the International Kinesio Taping Instructors in 2005 was an important step in popularizing and developing the method [6]. Among the leading instructors in Poland, who trained a multitude of physiotherapists and doctors, are Professor Zbigniew Śliwiński, Tomasz Senderek and Ireneusz Hałas [6].

The aim of this study was to present KT techniques and its application in various fields of medicine, sports and rehabilitation.

\section{MATERIAL AND METHODS}

The publications used in this paper were sourced from the PubMed and the Google Scholar databases. We searched for possible applications of Kinesio taping in sport, medicine, and dentistry. The index entries used to search the PubMed and Google Scholar browsers included KT, Kinesio taping, medicine, dentistry and sport.

Table 1. Physical properties of the tape [3]

\begin{tabular}{ll}
\hline Thickness and weight of taping material & Similar to the properties of the human skin \\
\hline Elasticity & Similar to the skin's elasticity (130\%-140\%) \\
Taping material & Acrylic coated cotton \\
Shape & Sinusoidal \\
Waterproof & Possibility of bathing, running and swimming with it \\
Permeable to air and water & Facilitating their flow \\
\hline
\end{tabular}

\section{THE IMPACT OF KINESIO TAPING ON HUMAN BODY}

Taping has its impact on the skin, causing it to lift and wrinkle. As a result, blood and lymph flows are improved and harmful metabolites removed, which, in turn, contributes to a reduction of inflammation [7]. Moreover, taping improves microcirculation, reduces swelling, and improves healing of musculoskeletal injuries [7]. Lifting also increases the space between the skin and muscles. As a result, the receptors of deep and superficial sensation situated beneath the skin are less irritated, thus the feeling of pain is reduced [8]. Furthermore, KT decreases the pressure under the skin, which causes regression of exudates and removes subcutaneous hemorrhages and blockages in lymphatic fluids. In addition, it 
normalizes the muscle and nerve tension, and, at the same time, restores homeostasis in the body, as well as stimulates the endogenous anesthetic system. Additionally, it supports the functions of joints by protecting, stabilizing and increasing their mobility, and stimulates deep sensations by causing an increase in mechanoreceptive and prioperceptive impulses [9, 10]. Radiological evidence confirms that KT causes mechanical deformations of the tissues beneath the tape [3]. Kase et al. argued that the use of Kinesio taping has some physiological effects, such as reduction in pain or abnormal sensations, facilitation of muscle movement, removal of blockages in the lymph fluid or subcutaneous hemorrhage and correction of the joint misalignment [2]. Table 2 presents indications and contraindication for the use of KT.

Table 2. Indications and contraindication for the use of KT [11]

\begin{tabular}{ll} 
Indications for the use of KT & Contraindications to the use of KT \\
\hline spine and joint pain & acrylic glue allergies \\
fascial nerve paralysis & various application intolerances \\
tennis player's and golfer's elbow & directly on open wounds and scars \\
sprains and joint dislocations & malignant tumors \\
limb paresis & open traumatic wounds \\
muscle damage & fresh scars \\
headaches and sinus aches & non-union fractures \\
rib injuries & deep vein thrombosis \\
menstrual pains & acute failure \\
postoperative sutures & erysipelas in mastectomy \\
edemas, exudations, hematomas & diabetes \\
hyper and hypomobility of joints & new tattoos \\
\hline
\end{tabular}

\section{TAPING PROCEDURE}

Before the tape is applied, the taping area should be degreased and disinfected. Additionally, the area should be hairless-otherwise, the tape will not adhere to the skin properly. The skin should be shaved at least 24 hours beforehand [12]. The application procedure of sticking the tape should be started/initiated by rubbing the tape in order to activate the glue-the hot one sticks better. When applying the tape to the skin, the tape should not be stretched, and its edges should be rounded off to prevent it from peeling off [12]. If the patient's position in which the technique is used is limited due to pain, the results could be achieved by tightening the tape. However, after the tape is applied, it is not advisable to use any direct heat carriers (infrared lamps, electrotherapy treatments). Sports activity can be undertaken after 30 minutes following the KT application [12, 13]. Taping removal is done using oil that causes no skin irritation. The tape should be removed following the direction of hairs on the skin, by firstly removing the skin from the tape [13].

\section{PATIENT'S REACTIONS TO KT [13]}

- $\quad$ Skin irritation - contact allergy (itching, burning, redness of the skin), often confused with an allergic reaction. During taping, an increased secretion of waste may occur; therefore, patients are recommended to hydrate frequently. Otherwise, sweat and salt crystals contained in sweat may be secreted under the patch, causing skin irritation.

- Tension blisters - may appear at the ends of the patch due to excessive tensile forces.

- Cold sensations after bathing - dry the tape with a towel by touching it lightly, not rubbing vigorously.

- Increased pain during application - remove the tape. 


\section{KT TECHNIQUES}

Contrary to popular belief, placing the tape requires the user's knowledge, experience and understanding how application techniques work [14]. There are six Kinesio taping techniques:

\section{Muscle teChNique [14]}

This is the most commonly used physiological technique. It is known that it supports or weakens muscle work. The applied tape should be unstretched, forming convolutions which lift the skin. The tape must be placed at a maximum distance from tendons. Exceptions may be made if the patient experiences pain resulting from their inability of assuming such a position (Fig. 1).

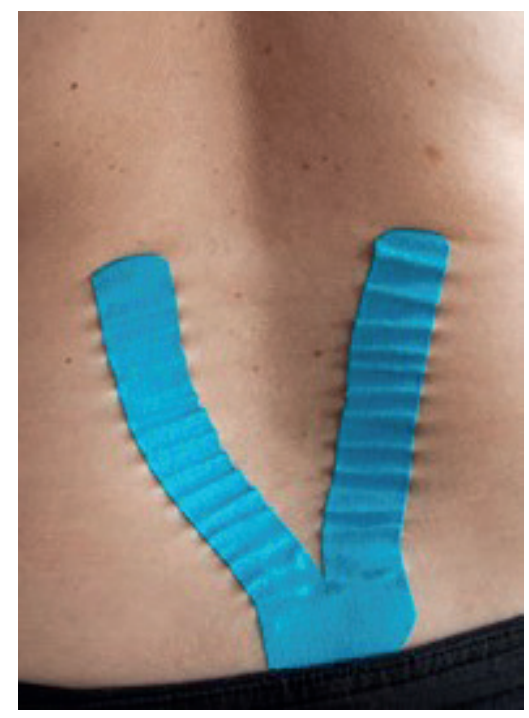

Fig. 1. Muscle technique

\section{LigAMENT TECHNIQUE [14]}

An I-shaped cutout. The main function of this technique is the lifting effect it has on the ligaments. Its main feature is the maximum degree of stretching in the central part of the tape $(100 \%)$, whereas the ends are applied without any stretching. The goal of this technique is to stimulate mechanoreceptors (Fig. 2).

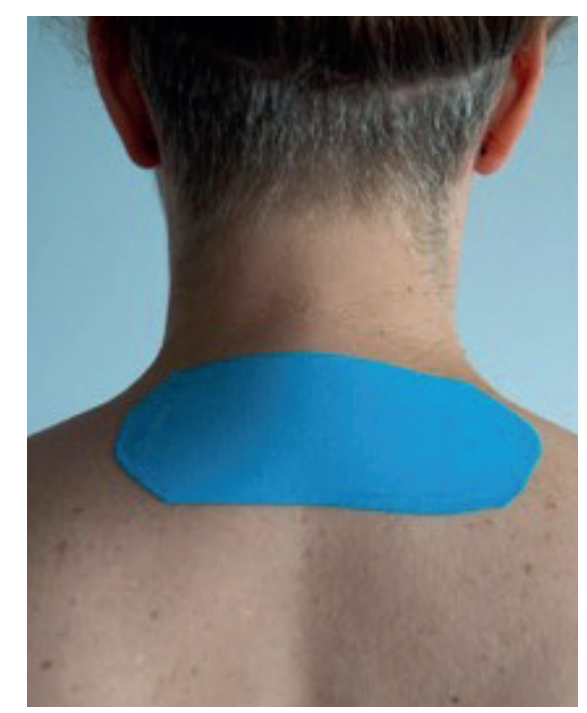




\section{FASCIAL TECHNIQUE [14]}

A V-shaped cutout. The purpose of this technique is to correct the positioning of fascia. The tape alleviates pain while the patient is moving. Typically, the applied tape is V-shaped. The $2 \mathrm{~cm}$ base of the tape should be applied without any tension, whereas both ends should be applied with a tension of about $25 \%$ (Fig. 3).

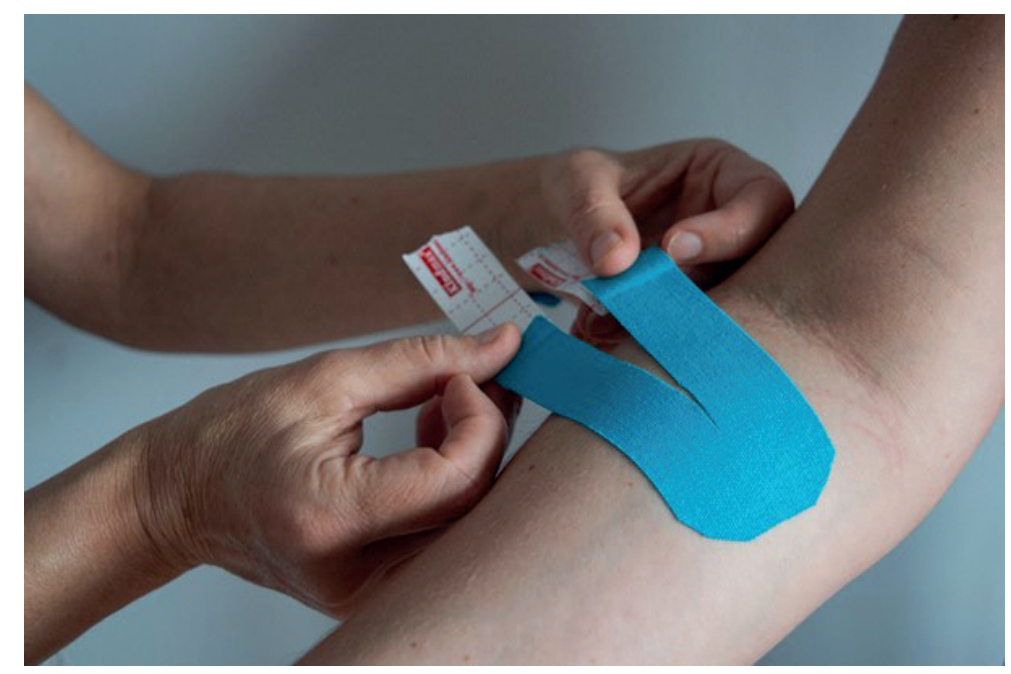

Fig. 3. Fascial technique

\section{Correction technique $[6,14]$}

It is known to increase the elasticity of tissue, causing a neutral positioning of muscles, joints and ligaments. The technique aims at correcting the range of motion. The patch is stretched by $50-70 \%$ of its length (Fig. 4).

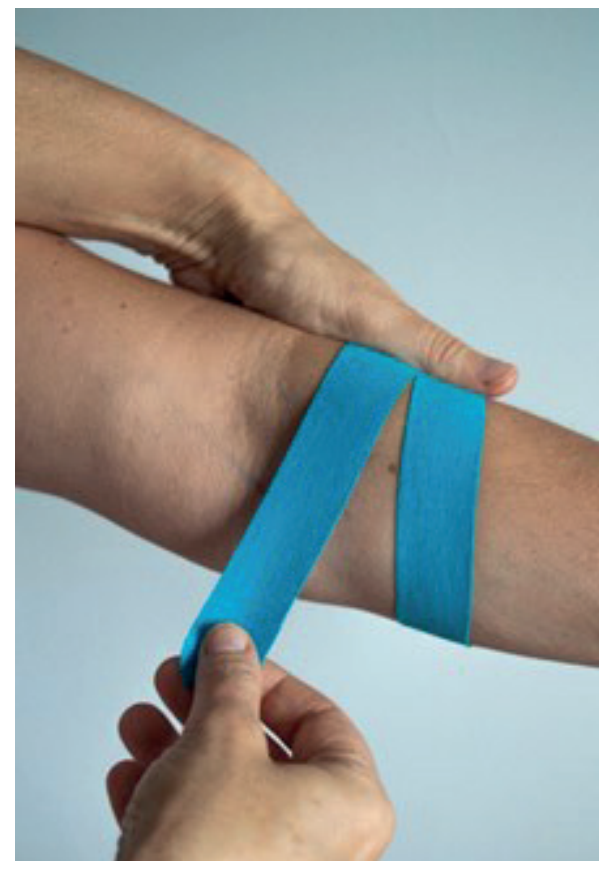

Fig. 4. Correction technique 


\section{LyMPHATIC DRAINAGE TECHNIQUE $[6,14]$}

It is implemented to reduce swelling and to improve proper lymphatic circulation. The Kinesio tape is cut into 4 parts in order to cover the swollen area, using approximately $10 \%$ of the tape's tension (Fig. 5).

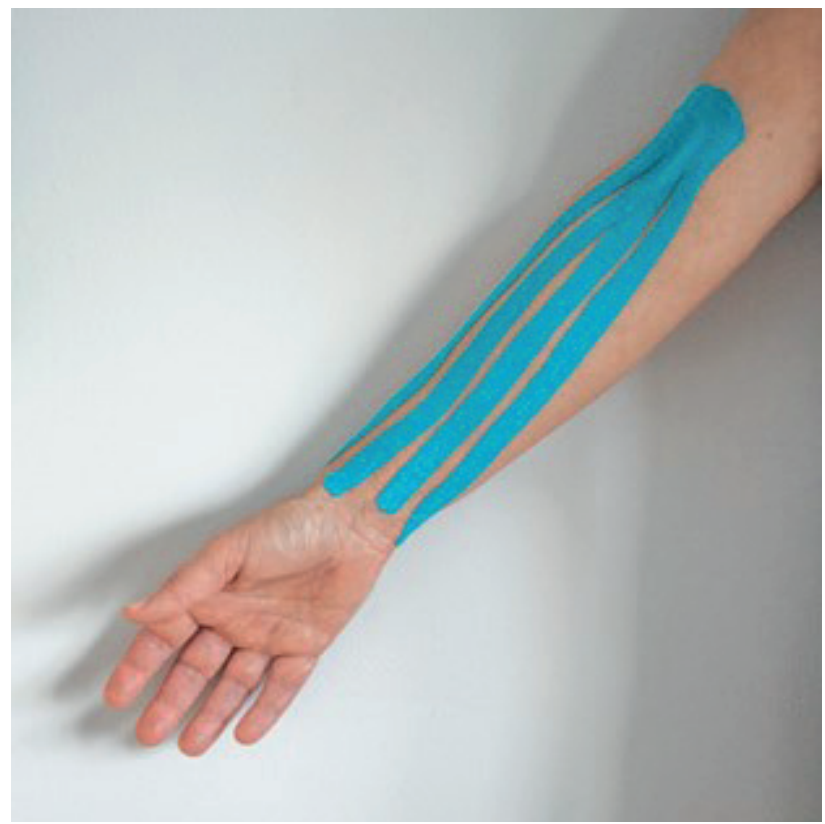

\section{Functional movement technique $[6,14,15,16]$}

It supports muscle paresis and dysfunctions of the upper and lower limbs, which improves their mobility as a result of stretching the tape by $50-75 \%$ (Fig. 6).

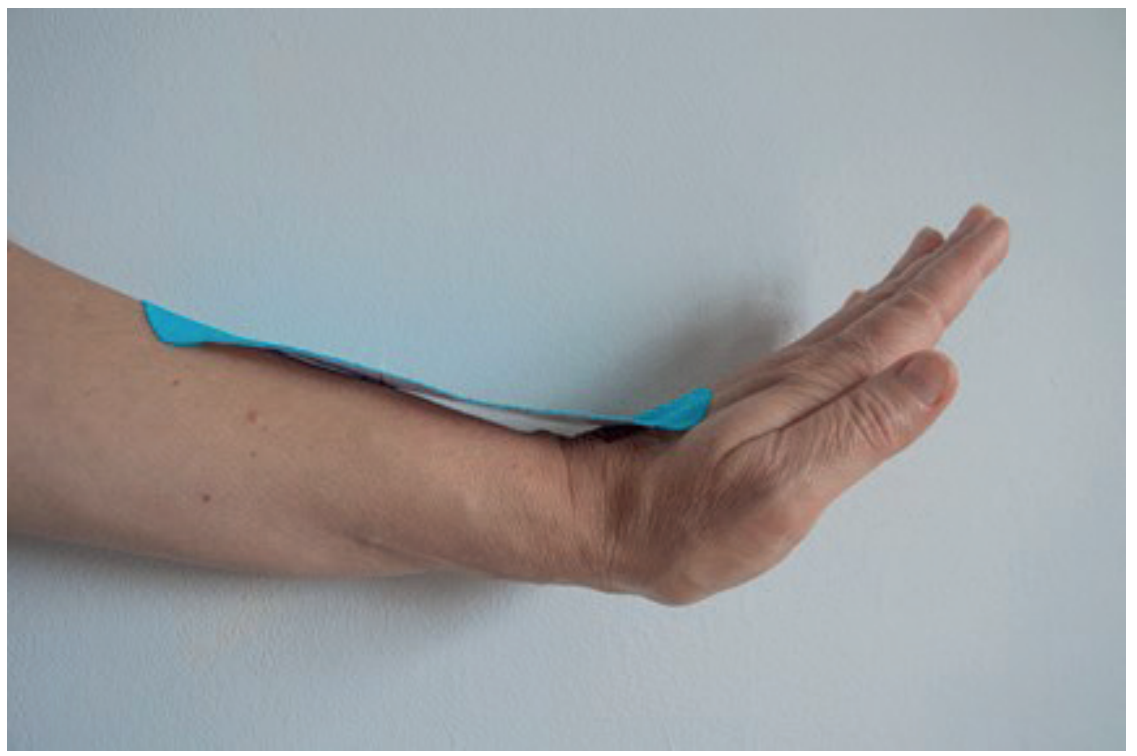




\section{Forms (shapes) OF the dynamic taping technique [12, 17]}

Taping applications in the dynamic taping technique may be in the form of letters I, Y, X, Fork and Slit I [12, 17].

I-shaped cutout is used in the case of muscle imbalances and damages; it is applied directly to where pain is located (Fig. 7).

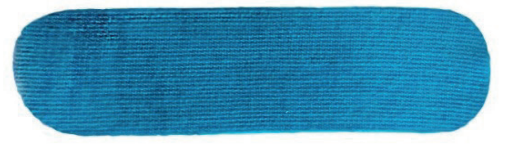

Fig. 7. I-shaped cutout

Y-shaped cutout is used to normalize muscle tension. The end of the tape is divided lengthwise to form two parts and should remain completely unstretched (Fig. 8).

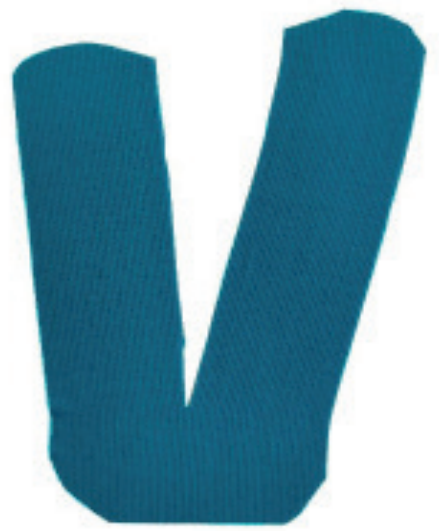

Fig. 8. Y-shaped cutout

X-shaped cutout is used for muscles with several sides, affecting two joints (Fig. 9).

Fig. 9. X-shaped cutout

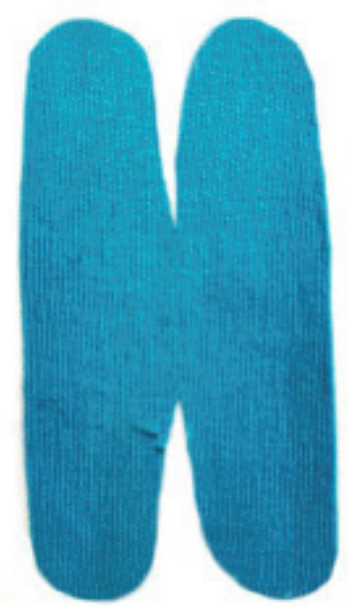


Fork-shaped cutout is colloquially called 'a fork'. An I-shaped strip is cut lengthwise into three pieces on one side of the tape. It is commonly used in lymphedema management or for superficial contusions and swelling (Fig. 10).

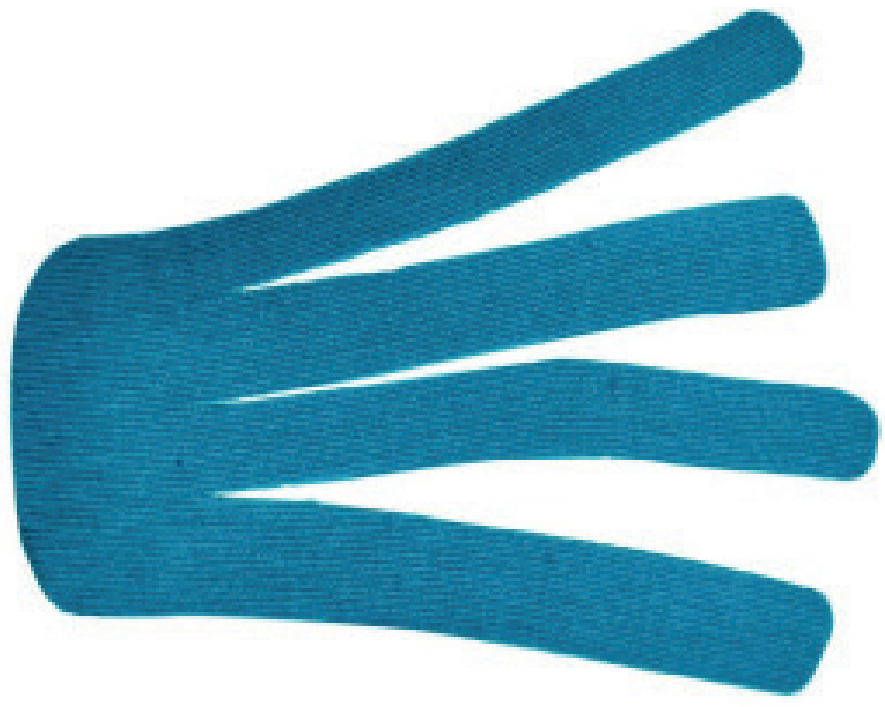

Fig. 10. Fork-shaped cutout

In the slit-shaped cutout the tape is cut in the middle into four or more pieces. It is applied in order to achieve an analgesic effect in the case of knee, elbow, and joint injuries, as well as in scar therapy and muscle imbalance (Fig. 11).

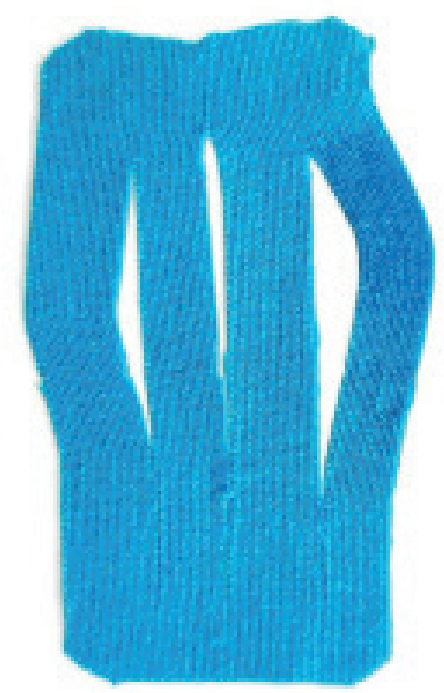

Fig. 11. Slit-shaped cutout

\section{KI APPLICATION}

\section{SPORT}

Since KT was first used in sports, there has been a growing interest in its vast array of applications. Its originator, Kenzo Kase, believed that the use of tapes could alleviate pain by stimulating the nervous system, strengthening muscles, reducing swelling and subcutaneous hemorrhages, as well as affect the proper alignment of the joints [18]. 
KT has become an important part of prophylaxis, manual therapy and rehabilitation in sports including swimming, soccer, handball, volleyball, baseball, or tennis [18]. In sports, such as handball and soccer, speed and muscle strength are considered to be key elements of the game tactic. As shown by the research conducted by Miller and Brandes [18], whose aim was to assess the impact of the KT application on shooting and throwing in soccer and handball, there was a considerable improvement in the ball speed when the players throw and shoot the ball [18]. This may be explained by the proprioceptive effect of KT on the athlete's body, which results in an increase in motor units contributing to muscle tone. Interestingly, these results indicate that the KT application to less skilled players could boost their performance [18].

Moreover, an increase in speed and accuracy of movements after the KT application was also observed among amateur tennis players [19]. The researchers' observations confirmed that the use of KT can reduce tissue inflammation and, consequently, pain. By stimulating proprioception, KT can regulate the posture by positioning the shoulder blades correctly, supporting the weakened rotator cuff muscles and the deltoid muscles [19, 20].

Kinesio taping was also studied on a group of swimmers. One of the main issues was shoulder pain caused by a prolonged duration of swimming, as a result of which the arm's excessive overhead movement led to mechanical impact. Consequently, the movement caused microinjuries, instability and changes in the pattern of shoulder movements [20].

Constant pain results in a need to take painkillers, and extensive injuries often lead to giving up sports. After applying KT to a group of swimmers who were over 18 years of age, with the tape placed directly on the location of pain, the results were delivered just after 30 minutes. The application of KT resulted in increased functional movement, increased flexibility and reduced pain in the back, arms, scapula and the cervical spine. The reason for the decrease in pain might be the effect of KT on the fascia, and thus the change of the pain area as a result of restoring the proper flow of superficial blood and normalizing the pressure - hence its reduction.

The practice of KT has shown that it has a positive effect on changes in the movement of the shoulder blade and muscle efficiency a mong a thletes practicing outdoor sports. Vellios et al. [21] have noticed that KT contributes to a positive change in the shoulder blade movement and muscle performance among basketball players. On the other hand, among athletes with the shoulder impingement syndrome, KT may affect the position of the shoulder blade and movement control. Kinesiology tape is a positional stimulus for the central nervous system [21].

On the other hand, in football, tendons of knees and hamstrings are the areas considered the most susceptible to injuries. The aforementioned ailments constitute $37 \%$ of all injuries associated with these tendons and have the highest recurrence rate. Most of the injuries in soccer $(75 \%)$ are known to be contact injuries resulting from high speed and aggressive tackling. In their study, Lee and Choi [22] used KT in a 25-year-old football player who had suffered a hamstring injury and traumatic knee pain. KT was applied after previous examination of the hamstring muscle - in a prone position, with a $20 \%$ of the tape stretching. It led to the application of two KT strips starting from the ischial tuberosity. The first one was attached to the semimembranosus muscle and the other to the biceps femoris muscle. To promote patellar inferior gliding, balance taping was applied from the patella towards both proximal tibia with a stretch of approximately 30 to $40 \%$, using the 2.5 -cm-wide kinesiology tape in a horseshoe shape. The horseshoe-shaped KT strip was applied around the patella towards both proximal tibia with a stretch of approximately $30-40 \%$. To strengthen tibial internal rotation, a kinesiology tape was then applied with a $50 \%$ overlap and approximately 
30 to $40 \%$ stretch. In order to stimulate the tibial internal rotation of the tibiofemoral joint, KT was applied medially by wrapping the 5 -cm-wide kinesiology tape from below the patella to the femur with a stretch of approximately 20 to $30 \%$. The result of this study showed that the patient was able to return to play due to decreased pain in the knee and an increased range of knee flexion. However, the case study has been conducted once [22].

\section{Orthopedics}

There is an inextricable link between sports and orthopedics, a link in which KT's growing popularity and use is combined with other therapeutic methods. In their research, Balki and Goktas [23] have documented the impact of KT on the acute postoperative rehabilitation phase of anterior cruciate ligament (ACL) reconstruction. Thirty male patients were divided into two groups in order to determine the impact of KT treatment on patients after ACL reconstruction and hamstring transplant. The first experimental group received KT treatment through the muscle and by means of lymphatic correction techniques. A Y-shaped correction tape with a tension of $25-30 \%$ was applied to the rectus femoris muscle, as well as to the hamstrings with a tension of 40-50\%. Lymphatic applications were placed in the direction of the nearest lymph nodes with a tension of $15 \%$, avoiding the postoperative sutures on the knee. Significant improvements were visible just after five days. The experimental group experienced a mitigation of pain and a significant reduction of swelling in the knee, as well as an increased knee flexion range of motion (ROM). In conclusion, the authors emphasize the importance of introducing the KT treatment techniques at an early stage of the rehabilitation process after ACL reconstruction as means of reducing swelling and alleviating pain [24]. Thelen used the KT method in a group of forty-two patients suffering from chronic rotator cuff disease. The aim of this method was to examine the impact of KT on pain sensations among patients as well as to increase the range of motion of the glenohumeral joint. The patients were divided into two groups. The Y-shaped muscle application was used in the first group, and the so-called "apparent" two I-shaped KT strips were used in the second group. Just after six days, both groups experienced alleviation of pain and a substantial increase in the range of motion of the glenohumeral joint [24].

A similar issue was explored by Carlos Lucas de Oliveri Benót Pairot de Fontenay et al. The main goal of their research was to investigate the influence of KT in combination with a rehabilitation program aiming at elimination or reduction of pain in the case of rotator cuff tendinopathy (RCT). The second aim was to research the impact of muscle on the control and range of motion in the glenohumeral joint. The study covered 52 participants divided into two groups of patients aged 18-65 [24]. In the experimental group, three applications of KT were used. The first Y-shaped tape with a tension of $15-25 \%$ was placed on the deltoid muscle in order to relax it. The second one was the I-shaped tape applied to achieve the multi-axis correction technique (tension 50-75\%) on the shoulder joint, including the supraspinatus, trapezius and medial deltoid. The third application of KT, also in the shape of letter I, had a corrective effect with a stretch of 50-75\% covering the shoulder. It was found that combining KT with other rehabilitation methods, such as manual therapy, may improve the athletes' quality of life [24]. Therefore, the research into this problem should be continued.

Correspondingly, Garcia-Muro et al. noticed the impact of KT methods on pain reduction in the case of rotator cuff tendinopathy (RCT) [25]. KT was introduced as a therapeutic method in the case of a 20-year-old swimmer diagnosed with rotator cuff inflammation, who - despite stopping the training, using anti-inflammatory drugs and physical therapy - showed no improvement for a period of one year. KT was applied on her deltoid muscle using the corrective and relaxing technique. Only after two treatments, she significantly improved mobility of the shoulder joint, increasing the extent of its abduction and flexion as well as reducing pain in the joint [25]. 


\section{Dentistry}

There has been a considerable increase in the amount of information regarding the use of $\mathrm{KT}$ in various fields of dentistry.

As noticed by Szarejko et al. [26], the progress of civilization, and thus living constantly under stress causes a negative impact on the stomatognathic system, causing its tension, contributing to the pain in the temporomandibular joints, the jaw and the mandible [26].

Teeth grinding and clenching are one of the most characteristic symptoms among this group of patients. Continuous clenching of teeth causes an increase in muscle tension in the craniofacial area, affecting distant muscle groups of the neck and shoulder and causing irritation and sensitivity of trigger points - these are easily palpable, painful thickenings within the muscles or fascia. They can be palpated as small grains, lumps, thickened stripes, or indurations. They are known to disrupt muscle movement patterns, causing contractions and, consequently, resulting in pain. The use of KT causes a gentle lifting effect of the skin, increasing the space between it and the muscles. As a result, the structures such as connective tissue, mechanoreceptors, fascia, muscles, joint capsules, trigger points and lymphatic vessels are exposed to less compression. It aims at relieving strained muscles in the head, neck and shoulder area, and, as a result of pain reduction, the quality of life improves [4].

Lietz-Kijak focuses her attention on the use of Kinesio taping in orthognathic surgery, as she deals with surgical intervention within the hard and soft tissues of the face and skull. The appearance of postoperative swellings causes considerable problems when it comes to tissue tension and increased pain sensations. Moreover, in her research she also concentrates on the reduction of swelling using the lymphatic KT method, which leads to a reduced tension in the affected area and restoration of proper lymphatic circulation, improving microcirculation in lymph and blood vessels [27].

A significant contribution in the self-healing processes of the body was observed, and, as a result, the reduction of swelling in the area affected by the process $[28,29,30]$.

On the other hand, Oliver Ristow et al. draw their attention to the fact that after OMF surgeries the clinical KT application has a positive influence on parameters such as trismus, pain, or swelling. Therefore, the patients after KT are considered to have a lower incidence rate [31].

Szarejko et al. reached interesting conclusions. They claim that in the case of edentulous patients with atrophy of the alveolar processes in the jaws and the alveolar part of the mandible, where the neuromuscular CT control is disturbed, KT may be a factor determining hypotonic stimulation. Moreover, KT might therefore support the retention of full dentures [26]. They also draw attention to the use of KT among groups of actors and opera singers, who, under the influence of stage fright, increase the tension of the diaphragm floor of the mouth. Kinesio taping may cause an increased relaxation of anatomical structures and thus holds a positive effect on the quality of speech [26].

\section{GYNECOLOGY}

Kinesio taping is becoming more common within the field of obstetrics. Lumbar spine pains, leg swelling, and lactation canal problems after childbirth are some of the most common issues faced by women.

Limited possibilities of taking painkillers during the course of pregnancy favors the usage of other therapeutic methods that are less invasive both for the mother and the newborn child. 
The previously mentioned pain in the lumbar region is a common affliction among women. It is estimated that it affects 45 to $75 \%$ of women. This particular dysfunction is often associated with relaxation of the ligaments and weakening of the pelvic floor and abdominal muscles. It results in a low quality of life and sleeping disorders, which many patients often treat as a norm. While examining the use of KT among pregnant women, Kaplan and Alpayc stated that KT could be safely used as an analgesic method that improves women's functioning during puerperium and improving their quality of life [32].

Consequently, Kuciel et al. have observed that KT might work in two ways: (1) by lifting the skin, it increases the space between the skin and the tissues, which improves blood circulation and the work of muscles. In return, it stabilizes ligaments and reduces the tension of the paraspinal muscles, whereas the second way (2) has its impact on skin receptors, counteracting pain and proprioception, thus positively influencing the posture [33].

Pregnancy is also a period of major changes in hormonal, cardiovascular and lymphatic systems, frequently resulting in an accumulation of large amounts of fluids between the tissues, which is often manifested by swelling of the ankle area, usually caused by a sedentary lifestyle, overweight, poor eating habits, lack of exercise or lymphatic dysfunctions - if there are no contraindications. It is important to mention that these symptoms are one of the most common complications amongst obese women during their later stages of pregnancy. In this case, it is recommended to apply the KT lymphatic techniques as well as muscle techniques [34].

After childbirth, lactation disorders commonly occur, which is manifested by milk invasion or lactation crisis - too little food is produced between the second and sixth week, and after 3 months. The first symptom is characterized by excessive food production, obstruction of the milk ducts and pain. The lymphatic application of KT, which is designed to unblock the exit ducts and allow milk to flow out, is recommended in addition to breast massage and warm compresses [35].

Another noteworthy and frequently used application of KT is associated with the C-section scar. The purpose of the application is to mobilize and make the scar more flexible, thus facilitating faster skin regeneration. The ligamentous technique is used with a stretch of $25-50 \%$ in the middle of the KT strip [35].

\section{NEUROLOGY}

Strokes are one of the most common and major diseases of the nervous system and, consequently, one of the biggest issues faced by medicine and rehabilitation. They constitute up to one third of all causes of death among today's adult population. They are also a cause of various disabilities of people over 45 years old. Common post-stroke complications include shoulder joint pain and shoulder joint dysfunctions. Commonly experienced shoulder pain often results from ineffective rehabilitation and poor patient care, which is why KT has been used widely in improving patients' condition after suffering a stroke. In their study, Kregiel and Iłżycka [37] investigated the use and application of KT in stroke patients with shoulder pain complex. The aim of the study was to evaluate the impact of KT on shoulder pain as well as on improvement in the upper limb function. The study included 64 men and 36 women between the age of 18 and 75. Each patient suffered a stroke, including an ischemic stroke or intracerebral hemorrhage. The application techniques followed the method used in Kinesio taping. The study has shown that the patients' pain levels were decreased just after 7 days following the first application. Moreover, the function of the upper limb was also improved by increasing the range of motion in the shoulder joint, thus contributing to a significant improvement in the patients' quality of life [37]. The analgesic efficacy of KT was also pointed out by Thelen et al. who compared the effects of KT and 
placebo in shoulder pain among young patients [38]. The KT therapy reduced the intensity of pain just after the first few days.

Furthermore, differences in the function of the upper limb among stroke patients were previously observed by Śliwiński [6]. A simultaneous application of the PNF method and the application of KT to the wrist extensors were found to improve the function of the upper limb. On the other hand, Michalak et al. have investigated the influence of KT on the improvement in gait patterns among patients after a stroke. As a result of their observations, they noticed an extension of the phase of gait support as well as an improvement in equalization of the stride’s length, and, therefore, faster transitions during the Up \& Go test [39].

Interesting studies on the effect of KT among neurological patients were presented by Varalta et al. [36] who examined patients experiencing Hemispatial Neglect (HN). HN is a neuropsychological condition caused by a stroke in which the patient experiences reduced consciousness. It is commonly contralateral to the damaged hemisphere - usually the left side. In practice, it looks as if the damaged side is nonexistent. This dysfunction may cause postural control disorders, postural instability, and, consequently, lead to falling. Their examination was aimed at assessing KT of the neck for visual-spatial abilities, cervical mobility and kinesthetic sensitivity of patients after a stroke. For this purpose, two groups using KT applications were included in the study. In the treatment group, the patch was applied from the reticular process to the sternoclavicular muscle towards the sternum with a tension of $15-25 \%$. Sticking the tape in this way raises the skin, and, therefore, increases the space between it and the tissues. It results in a better flow of lymph and blood around the neck, which, in turn, stimulates proprioception. In the control group, the tape was applied to the same place, but without tension. The results of their research coincided with the previously conducted research, suggesting that KT causes a sensory change through its stimulus effect on the skin, and thus contributes to the reduction of spasticity caused by feedback [36]. It also turned out that patients in the treatment group had an ability to move their heads towards the torso in the horizontal plane, as opposed to patients from the control group, in which this type of movement was nonexistent. They also improved the increased range of neck mobility in the direction of flexion, rotation and extension and the right tilt of the neck. A slight improvement in the visual-spatial abilities was observed among both groups. However, the authors pointed out that KT might be a very useful therapeutic tool in patients with HN, since it improved their motor skills and neck kinesthetic [36].

KT's effects are also visible in the paralysis of facial muscles, which often accompanies stroke patients [40, 41]. The application of KT supports facial movements, reduces muscle tension, normalizes the symmetries of the face, which results in the patients experiencing fewer problems when speaking, eating and drinking. Techniques and methods of cutting the patch are selected for each patient individually [42].

\section{CONCLUSIONS}

Based on this study, it can be concluded that KT is the most recommendable method. Its use is being increasingly popular in many fields of medicine, including neurology, orthopedics, sports, gynecology, and dentistry. It can be considered as an alternative for painkillers, especially in patients for whom the use of painkillers is not advisable or ineffective due to their condition - it does not burden the body as much as medications. Because KT uses the vast array of the above-mentioned techniques, it exerts anti-swelling, corrective, stabilizing and analgesic effects. It provides promising and effective results when combined with other techniques. KT is not a complicated method, let alone costly. It is well tolerated by patients, and saves time; therefore, its use should be taken into account in various medical environments. In order to use this method, one should complete specialized courses, which, 
on the one hand, provide theoretical basis for its use, and on the other hand, teach how to choose original tapes in a practical way, as well as apply appropriate techniques in order to observe and compare the effects of one's work - therapy and treatment.

\section{ACKNOWLEDGEMENTS}

This article was written during a scientific training session in the Champions-Implants GmbH; Champions Platz 1; D-55237 Flonheim, Germany.

\section{REFERENCES}

[1] Kiebzak W, Kowalski IM, Pawlowski M, et al. Wykorzystanie metody Kinesiology Taping w praktyce fizjoterapeutycznej: przegląd literatury [The use of the Kinesiology Taping method in physiotherapeutic practice: a literature review]. Fizjoterapia Polska. 2012;12(1):1-11. Polish. doi: 10.5604/16420136.990847

[2] Kase K, Wallis J, Kase T. Clinical therapeutic applications of Kinesio taping method. 2nd ed. Tokyo, Japan: Ken Ikai co. Ltd, 2003.

[3] Banerjee G, Briggs M, Johnson MI. The immediate effects of kinesiology taping on cutaneous blood flow in healthy humans under resting conditions: A randomised controlled repeated-measures laboratory study. PLoS One. 2020;15(2):e0229386. doi: 10.1371/journal.pone.0229386

[4] Lietz-Kijak D, Kopacz L, Ardan R, Grzegocka M, Kijak E. Assessment of the short-term effectiveness of Kinesiotaping and trigger points release used in functional disorders of the masticatory muscles. Pain Res Manag. 2018 May 10;2018:5464985. doi: 10.1155/2018/5464985. PMID: 29861804; PMCID: PMC5971356.

[5] Kalinowski P, Krawulska A. Kinesio taping vs. placebo in reducing pregnancy-related low back pain: A cross-over study. Med Sci Monit. 2017;23:6114-6120. Published 2017 Dec 26. doi: 10.12659/msm.904766

[6] Śliwiński Z, Krajczy M. Dynamiczne plastrowanie [Dynamic taping]. Wrocław: Markmed - Rehabilitacja, 2014. Polish.

[7] Abolhasani M, Halabchi F, Afsharnia E, et al. Effects of kinesiotaping on knee osteoarthritis: A literature review. J Exerc Rehabil. 2019;15(4):498-503. doi: 10.12965/jer.1938364.182

[8] Öztürk G, Külcü DG, Mesci N, Şilte AD, Aydog E. Efficacy of kinesio tape application on pain and muscle strength in patients with myofascial pain syndrome: a placebo-controlled trial. J Phys Ther Sci. 2016;28(4):1074-1079. doi: 10.1589/jpts.28.1074

[9] Selva F, Pardo A, Aguado X, et al. A study of reproducibility of kinesiology tape applications: review, reliability and validity. BMC Musculoskelet Disord. 2019;20:53. doi: 10.1186/s12891-019-2533-0

[10] Karatas N, Bicici S, Baltaci G, Caner H. The effect of Kinesiotape application on functional performance in surgeons who have musculoskeletal pain after performing surgery. Turk Neurosurg. 2012;22:83-89. doi: 10.5137/1019-5149. JTN.5377-11.1

[11] Medrak A, Krol T, Michalek-Krol K, Dabrowska-Galas M. Kinesiotaping a efekt placebo [Kinesiotaping and the placebo effect]. Medycyna Rodzinna. 2017;4:304-309. Polish. doi: 10.25121/MR.2017.20.4.304

[12] Ramin I. Taping. Zastosowanie kliniczne. Techniki. Efekty terapii [Taping. Clinical application. Techniques. Effects of therapy]. Wrocław: Edra Urban Partner, 2018. Polish.

[13] Mikołajewska E. Kinesiotaping - rozwiązanie wybranych problemów [Kinesiotaping - a solution to selected problems]. Warszawa: Wydawnictwo Lekarskie PZWL, 2011. Polish.

[14] Radgowska E. Zastosowanie Kinesiology Taping w terapii logopedycznej [The use of Kinesiology Taping in speech therapy]. Głos-Język-Komunikacja. 2019;6:1-12. Polish. doi: 10.15584/978-83-7996-731-5_12

[15] Zait-Kwiatkowska J, et al. Kinesiotaping metoda wspomagająca proces usprawniania fizjoterapeutycznego - wybrane aplikacje kliniczne [Kinesiotaping a method supporting the process of physiotherapeutic improvement - selected clinical applications]. Nowiny Lekarskie. 2005;74(2):190-194. Polish.

[16] Weber-Rajek M, et al. Ocena skuteczności Kinesiotapingu w terapii dolegliwości bólowych lędźwiowo-krzyżowego odcinka kręgosłupa [Evaluation of the effectiveness of Kinesiotaping in the treatment of pain in the lumbosacral spine]. Med Biol Sci. 2011;25(1):59-64. Polish.

[17] Markowski A. Kinesiotaping, praktyczny poradnik, techniki korekcyjne, aplikacje mięśniowe [Kinesiotaping, practical guide, corrective techniques, muscle applications]. Warszawa: Wydawnictwo SBM Sp. z o.o., 2015. Polish.

[18] Müller C, Brandes M. Effect of Kinesiotape Applications on Ball Velocity and Accuracy in Amateur Soccer and Handball. J Hum Kinet. 2015 Dec 30;49:119-29. doi: 10.1515/hukin-2015-0114. PMID: 26839612; PMCID: PMC4723160.

[19] Boguszewski D, Dobrowolska J, Białoszewski D. Assessment of the effects of kinesiotaping on selected elements of physical fitness in middle-aged, amateur tennis players. TRENDS in Sport Sciences. 2016;2(23):105-112.

[20] Hanson JH, Ostrem JD, Davies BL. Effect of Kinesiology Taping on upper torso mobility and shoulder pain and disability in US Masters National Championship swimmers: An exploratory study. J Manipulative Physiol Ther. 2019 May;42(4):247-253. doi: 10.1016/j.jmpt.2018.11.009. Epub 2019 Jun 17. PMID: 31221494.

[21] Vellios EE, Pinnamaneni S, Camp CL, et al. Technology used in the prevention and treatment of shoulder and elbow injuries in the overhead athlete. Curr Rev Musculoskelet Med. 2020;13:472-478. doi: 10.1007/s12178-020-09645-9

[22] Lee SM, Lee JH. Effect of balance taping using kinesiology tape for a hamstring muscle injury and traumatic knee pain in an amateur university football player: A case report. Medicine (Baltimore). 2018 Jun;97(23):e10973. doi: 10.1097/MD.0000000000010973. PMID: 29879050; PMCID: PMC5999489.

[23] Balki S, Göktaş HE, Öztemur Z. Kinesio taping as a treatment method in the acute phase of ACL reconstruction: A double-blind, placebo-controlled study. Acta Orthop Traumatol Turc. 2016 Dec;50(6):628-634. doi: 10.1016/j. aott.2016.03.005. Epub 2016 Oct 24. PMID: 27784622; PMCID: PMC6197419. 
[24] Mosiejczuk H, Lubinska A, Ptak M, et al. Kinesiotaping as an interdisciplinary therapeutic method. Pomeranian J Life Sci. 62(1):60-6. doi: 10.21164/pomjlifesci.171

[25] Garcia-Muro F, Rodriguez-Fernandez A, Herrero-de-Lucas A. Treatment of myofascial pain in the shoulder with Kinesio taping. A case report. Manual Ther. 2010;15(3):292-295. doi: 10.1016/j.math.2009.09.002

[26] Szarejko K, Kuc J, Aleksandrowicz K, Golebiewska M. The essence of kinesiotaping in the craniomandibular and craniofacial areas. A literature review. Part I Prosthodontics 2016;66(5):359-366. doi: 10.5604/.1222597

[27] Lietz-Kijak D, Kijak E, Krajczy M, Bogacz K, Łuniewski J, Szczegielniak J. The impact of the use of Kinesio Taping method on the reduction of swelling in patients after orthognathic surgery: A pilot study. Med Sci Monit. 2018 Jun;24:3736-3743. doi: 10.12659/MSM.909915. PMID: 29861496; PMCID: PMC6015478.

[28] Jaron A, Preuss O, Grzywacz E, Trybek G. The impact of using Kinesio Tape on non-infectious complications after impacted mandibular third molar surgery. Int J Environ Res Public Health. 2021 Jan.;18(2):399. doi: 10.3390/ ijerph18020399. PMID: 33419167; PMCID: PMC7825547.

[29] Jaron A, Jedlinski M, Grzywacz E, Mazur M, Trybek G. Kinesiology Taping as an innovative measure against postoperative complications after third molar extraction - Systematic review. J Clin Med. 2020 Dec.;9(12):3988. doi: 10.3390/jcm9123988. PMID: 33317073; PMCID: PMC7763842.

[30] Preuss O, Jaron A, Trybek G. Plastrowanie dynamiczne w chirurgii stomatologicznej [Dynamic taping in dental surgery]. Stomatologia po dyplomie. 2020;11-12. Polish.

[31] Ristow O, Pautke C, Kehl V, Koerdt S, Hahnefeld L, Hohlweg-Majert B. Kinesiologic taping reduces morbidity after oral and maxillofacial surgery: a pooled analysis. Physiother Theory Pract. 2014 Aug;30(6):390-8. doi: 10.3109/09593985.2014.891068. Epub 2014 Feb 27. PMID: 24575949.

[32] Kaplan S, Alpayci M, Karaman E, et al. Short-term effects of kinesio taping in women with pregnancy-related low back pain: A randomized controlled clinical trial. Med Sci Monit. 2016 Apr.;22:1297-301. doi: 10.12659/msm.898353. PMID: 27088271 ; PMCID: PMC4837927.

[33] Kuciel N, Sutkowska E, Cienska A, Markowska D, Wrzosek Z. Myoelectrical activity of muscles stabilizing the sacroiliac joints before and after the use of elastic tapes in women suffering from Pregnancy-related Pelvic Girdle Pain. Ginekol Pol. 2020;91(4):223-230. doi: 10.5603/GP.2020.0044. PMID: 32374023.

[34] Korabiusz K, Wawrykow A, Torbé D, Torbé A. Lymphedema during pregnancy - Case study. J Educ Health Sport. 2017 June;7(6):397-407. doi: 10.5281/zenodo.817729.

[35] Slomko W, Zamojska P, Dzierzanowski M. Physiotherapy in the postpartum problems. J Educ Health Sport. 2017 Apr.; 7(4):323-333

[36] Varalta V, Munari D, Pertile L, et al. Effects of neck taping in the treatment of hemispatial neglect in chronic stroke patients: A pilot, single blind, randomized controlled trial. Medicina (Kaunas). 2019;55(4):108. doi: 10.3390/ medicina55040108

[37] Kregiel A, Ilzecka J. The use of Kinesio Taping in the treatment of pain and shoulder dysfunction in patients after stroke. J Educ Health Sport. 2018 March;8(3):88-103.

[38] Thelen MD, Dauber JA, Stoneman PD. The clinical efBicacy of kinesio tape for shoulder pain: a randomized, double -blinded, clinical trial. J Orthop Sport Phys Ther 2008;7(38):389-96. doi: 10.2519/jospt.2008.2791

[39] Michalak B, Halat B, Kufel W, et al. Ocena stereotypu chodu po zastosowaniu Kinesiology Tapingu u pacjentów po udarze mózgu [Assessment of the gait stereotype after the application of Kinesiology Taping in patients after stroke]. Fizjoter Pol. 2009;2(4):133-42. Polish.

[40] Sasinowski J. Kinesio Taping w porażeniu nerwu twarzowego - opis przypadku [Kinesio Taping in facial nerve palsy - Case study]. Rehabilitacja w praktyce. 2012;6:37-41. Polish.

[41] Kiebzak W, Szmigiel Cz, Sliwinski Z, Zieba M. Porownanie koncepcji usprawniającego usprawnienia w uszkodzeniach nerwu twarzowego $u$ dzieci [A comparison of concepts of improving in facial nerve injuries in children ]. Fizjoterapia Polska. 2006;6(1):22-26. Polish.

[42] Bauer A, Wiechec M., Przewodnik metodyczny po wybrane zabiegach fizykalnych [Methodological guide to selected physical treatments]. Ostrowiec Świętokrzyski: Wydawnictwo Markmed Rehabilitacja, 2005. Polish. 